\title{
Reading and Sharing WhatsApp Forwarded Messages
}

\author{
Wahid Hasim ${ }^{1}$, Muhamad Taufik Hidayat ${ }^{2}$, Amir Hamzah $^{3}$, Nuraeni $^{4}$ \\ \{wahidhasim2807@gmail.com ${ }^{1}$, mtaufikhidayat637@gmail.com ${ }^{2}$, amirhamzahgrt@ gmail.com ${ }^{3}$ \} \\ Institut Pendidikan Indonesia, Jl. Terusan Pahlawan No.83, Garut $44151^{1}$, Institut Pendidikan \\ Indonesia, Jl. Terusan Pahlawan No.83, Garut $44151^{2}$, Institut Pendidikan Indonesia, Jl. Terusan \\ Pahlawan No.83, Garut $44151^{3}$
}

\begin{abstract}
WhatApps is the social media platform with enormous users. In WhatsApp, the user can share and get various information from friends or groups. However, there are many messages that cannot be confirmed factually. Many people just believe that forwarded messages or messages or information without rethinking the reliability of the information. Most of these come from an unreliable source and comes along with misinterpretations and misinformation. Concerned with the fact, this research is aimed to analyze people awareness in reading and sharing forwarded WhatsApp messages. The participant of this research is fifty participants from various social background. The result found most WhatsApp user tend to ignore the validity of the information and impatiently share what they read from the message. However, there are some others who critically read the text before sharing and forwarding it. The result of this study is expected to stimulate more law enforcement in dealing and filtering information shared by the community.
\end{abstract}

Keywords: Technological development, Information exchange, forwarded messages.

\section{Introduction}

At present rapid developments in technology, politics, sociology, economics, and science and all aspects cause noteworthy changes in human life [1]. Society is encouraged to adapt and to live according to this new standard. Information is exchanged rapidly. People need to learn faster, think multidimensional and be creative to settle for the new consequences in their lives. Along with this developmental change, there is a greater prevalence of science misinformation available to the public. This issue is particularly problematic for novices who often believe that science in the media is factual and objective [2]. On the other hand, an educated society that can understand how to apply information to the world is fundamental to future growth [3]. To know what is true, individuals sometimes have to think about what is false. Unfortunately, they do not often follow this precept. When they reason, they usually consider only what is true [4]. Furthermore, in the context of a certain political condition, much has been written about the spread of false information on social media and websites [5]. Also, there is a large body of research in social psychology showing that people tend to believe what they should not [6]. The menace of misinformation online has gained considerable media attention, and plausible solutions for combatting misinformation have often been less than satisfactory [7]. It is crucial that researchers and policy makers be attracted to highlight this gap. Better understanding of information distributed in the social media offer burning issue to be analyzed. 
WhatsApp has been widely used around the globe. It is deemed as one of the most popular instant communication platforms [8]. Over fifty million users had downloaded WhatsApp when it was first launched in 2009 [9]. It has grasped an intense growth, with reports signifying an increase of up to 1 million users per day, it means that WhatsApp has daily engagement higher than the industry standard [10]. It lets its users send and receive messages such as emoticons, pictures, voice notes, videos and web links [9]. Many people and members of specific groups, such as university classmates, parents at school, co-workers, family, and friends, have adopted WhatsApp as their most preferred form of communication [8].

Nevertheless, smartphone applications such as WhatsApp are not without limitations and risk for their users [11]. From WhatsApp, people will get forwarded message that could not be confirmed the validity. To overcome this problem, readers should think critically when they got WhatsApp Forwarded messages. Critical thinking is the process of questioning the source of knowledge, testing the validity of the acquired information, analyzing its reliability, and drawing appropriate explanations for specific tasks or situations [12]. Reader will be aware of WhatsApp forwarded messages validity when they conduct the process of critical thinking. People would not send WhatsApp Forwarded messages arbitrarily when they realize that not all of these messages are valid.

\section{Method}

The study was carried out under a qualitative approach in which fifty participants were voluntarily involved. They were asked personally to participate and to provide their experience of using and sharing WhatsApp forwarded message. The participants involved varied in their social background. This was done to ensure that this study captured the phenomena from the different social status point of views. They were given questionnaires related to their habit of using and dealing with WhatsApp forwarded message. The questionnaires cover such aspects as: testing the validity of the acquired information, analyzing its reliability, and drawing appropriate explanations for specific tasks or situations [12]. They are in line with the main concept of critical thinking stating that critical thinking is a conscious and deliberate process used to interpret or evaluate information and experiences with a set of reflective attitudes and abilities that guide thoughtful beliefs and actions [1]. These parameters were used as the guidelines in analyzing the participants' responses. The participants were then classified as numbers of categories: housewives, lecturers, teachers, graduate students, undergraduate students. Also, the participants were also active WhatsApp users. This was done to ensure that they had the experience(s) of reading and sharing the WhatsApp forwarded messages. They were asked whether they critically understand the message they shared and forwarded.

\section{Result and Discussion}

At the start, the study provides the result from the questionnaires. What follows are the descriptions of respondents answer on their habit in reading and sharing WhatsApp forwarded message. 
Table 1. Response on questionnaires 1

\begin{tabular}{llcc}
\hline No & \multicolumn{1}{c}{ Participants } & \multicolumn{2}{c}{ checking the validity of the acquired information } \\
\cline { 3 - 4 } & & Yes & No \\
$\mathbf{1}$ & Housewives & 2 & 4 \\
$\mathbf{2}$ & Lecturers & 4 & 2 \\
$\mathbf{3}$ & Teachers & 8 & 5 \\
$\mathbf{4}$ & undergraduate students & 4 & 4 \\
$\mathbf{5}$ & graduate students & 3 & 4 \\
$\mathbf{6}$ & office workers & 3 & 7 \\
\hline
\end{tabular}

Table 1 displays the result of-of questionnaires 1 . In this section, the participants were asked if they had checked the validity of the information before they shared the messages. Surprisingly from the result, it was found that, only $48 \%$ of participants who critically check the validity of the information. They tend to neglect the source and the accuracy of the forwarded message they received. As presented in table $52 \%$ of people ignore the validity of the information contained in the message.

From the data, It was revealed that most of the participant ignore the validity of the information; they did not think whether the information was valid or not. In other words, they tend to ignore the source of the information and the evidence supporting the information. However, the classification of the participants' social background has brought up a different dimension. Table 1 showed that lecturers and teachers are among the top list considering the information validity. On the other hand, office workers are those who tend to neglect the information validity before they share the information.

Table 2. Response on questionnaires 2

\begin{tabular}{llcc}
\hline No & \multicolumn{1}{c}{ Participants } & \multicolumn{3}{c}{ Analyzing its reliability } \\
\cline { 3 - 4 } & & Yes & No \\
$\mathbf{1}$ & Housewives & 2 & 4 \\
$\mathbf{2}$ & Lecturers & 3 & 3 \\
$\mathbf{3}$ & Teachers & 6 & 7 \\
$\mathbf{4}$ & undergraduate students & 3 & 5 \\
$\mathbf{5}$ & graduate students & 2 & 5 \\
$\mathbf{6}$ & office workers & 4 & 6 \\
\hline
\end{tabular}

Table 2 shows the distribution of respondents answers. The result discovered that $60 \%$ of the respondents failed to analyze the reliability of the WhatsApp forwarded messages. And 40 $\%$ of the participants could analyze the reliability of the information. Teachers are the most participants analyzing information reliability. By analyzing the source and the authorship of the information, one may be able to ensure information reliability. In this context of critical thinking, graduate students are those who are the least to analyze information reliability. The amount is somewhat similar to housewives. They may be likely to distribute false information since they fail to identify reliable information. It is such a relieving fact that educated people represented by lecturers and teachers value the reliability of information source. However, the fact revealed from this analysis has brought significant concerns. The overall numbers or the proportion are too high too tolerate 
Table 3. Response on questionnaires 3

\begin{tabular}{llcc}
\hline No & \multicolumn{1}{c}{ Participants } & \multicolumn{2}{c}{$\begin{array}{c}\text { Drawing appropriate explanations for specific tasks or } \\
\text { situations }\end{array}$} \\
\cline { 3 - 4 } & & Yes & No \\
$\mathbf{1}$ & Housewives & 1 & 5 \\
$\mathbf{2}$ & Lecturers & 2 & 4 \\
$\mathbf{3}$ & Teachers & 5 & 8 \\
$\mathbf{4}$ & undergraduate students & 2 & 6 \\
$\mathbf{5}$ & graduate students & 2 & 5 \\
$\mathbf{6}$ & office workers & 3 & 7 \\
\hline
\end{tabular}

Table 3 shows the respond of the participants. The result shows that $70 \%$ of the participants failed to draw appropriate explanations for specific tasks or situations, and $30 \%$ of participants could draw the appropriate explanations for specific tasks. It means that participants generally failed to get comprehen information about the message. They tend to believe what is unconfirmed information.

Based on the result of the study it can be concluded that most of the people tend to ignore the validity of the information and they will spread the information without thinking reliability. But few of them read critically and think about the validity or reliability of the information.

As the description of the finding emerged, it can be deduced that society critical thinking is somewhat questionable. The number of the unreliable source of information has been flourishing significantly. Combined with the ignorance and lack of critical thinking, false information has been distributed irresponsibly. Given the numbers obtained from the questionnaires, $40 \%$ or even $50 \%$ is too high for false information to be spread in civilization. To name a few; Hate speech, hoax, black campaign, propaganda, misinformation, false information are types of what-so-called the forwarded message contents. However, to certain extents, the current study focuses more on society awareness in dealing with this phenomena. The further analysis may be carried out more on the content of this type of shared messages.

\section{Conclusions}

To conclude, the ability to critically process information is important. This critical skill in reading affected one's ability in responding to the message. It is critical to nowadays context as the abundance of forwarded message is flooding in our society. It is important that every individual pause before sharing the forwarded message they read. They need to understand before sharing and forwarding the messages. Unreliable information source, irresponsible act of sharing and forwarding, impatiently and emotionally sharing the unreliable contents are things that are commonly found in today society. There needs to be more social awareness to understand the information before forwarding and sharing the contents. The principle concepts of critical thinking need to be well established within society. Understanding, interpreting and evaluating information are what people neglected based on the finding of this study. Based on the result of this study, further research is expected to bring up social awareness to read and think critically in responding the technological development. Furthermore, policy makers and 
law enforcers are suggested to establish more strict rules in governing these information exchange activities. The rules are not to limit society freedom in sharing valuable information. They are established to establish standards, maintain order, resolve disputes, and protect liberties and rights.

\section{Acknowledgment}

The authors would like to express the deepest appreciation to Institut Pendidikan Indonesia for supporting the publication process of this article.

\section{References}

[1] Topoglu, O.: Critical Thinking and Music Education. Procedia - Social and Behavioral Sciences. pp. 2252-2256 (2014)

[2] Tseng, A. S.: Students and evaluation of web-based misinformation about vaccination: critical reading or passive acceptance of claims?. International Journal of Science Education, Part B. pp. 250-265 (2018)

[3] Swanson, T. A.: Applying a Critical Pedagogical Perspective to Information Literacy Standards. Community \& Junior College Libraries. pp. 65-77 (2005)

[4] Newsome, M. R, Johnson-Laird P. N.: How falsity dispels fallacies. Psychology press. pp. 214$234(2006)$

[5] Wells, D. D.: You All Made Dank Memes: Using Internet Memes to Promote Critical Thinking. Journal of Political Science Education. pp. 240-248 (2018)

[6] Chen, Y.: Unwanted Beliefs: Age Differences in Beliefs of False Information. Aging, Neuropsychology, and Cognition. pp. 217-230 (2002)

[7] Khan, M. L, Idris I. K.: Recognise misinformation and verify before sharing: a reasoned action and information literacy perspective. Behaviour \& Information Technology. pp. 1-19 (2019)

[8] Flores-Salgado, E, Castineira-Benitez, T.A.: The use of politeness in WhatsApp discourse and move 'requests'. Journal of Pragmatics. pp. 79-92 (2018)

[9] A. Sánchez-Moya, A, Cruz-Moya, O.: Whatsapp, Textese, and Moral Panics: Discourse Features and Habits Across Two Generations. Procedia - Social and Behavioral Sciences. pp. 300-306 (2015)

[10] Duran, E, Yalçinta,E.: Review of The Critical Reading Education in The Primary Schools. Procedia - Social and Behavioral Sciences. pp. 1560 - 1566 ( 2015 )

[11] Brewster, C. T.:Correspondence and Communication. Journal of Plastic, Reconstructive and Aesthetic Surgery. pp. 705-706 (2017)

[12] Muglia, S, et all.:Creative and critical thinking : Independent or overlapping components ? Thinking Skills and Creativity. pp. 114-122 (2018) 